\title{
POEMS syndrome - a unique presentation of a rare paraneoplastic syndrome
}

\author{
J Livingston, ${ }^{1}$ C Cobiella, ${ }^{2}$ M A Hall-Craggs ${ }^{3}$ \\ ${ }^{1}$ Accident and Emergency Department, Basildon and Thurrock University Hospital, Nethermayne, Essex, UK \\ ${ }^{2}$ Department of Orthopaedics, University College Hospital, London, UK \\ ${ }^{3}$ Department of Radiology, University College Hospital, London, UK
}

Correspondence to J Livingston, judithlivingston@hotmail.co.uk

\section{Summary}

POEMS (peripheral neuropathy, organomegaly, endocrinopathy, M protein, skin changes) syndrome is a rare multisystem paraneoplastic disorder. A 40-year-old male with a history of peripheral neuropathy and erectile dysfunction presented with a pathological fracture of the neck of the femur, found to be a solitary plasmacytoma. Additional unusual features included splenomegaly, hyperprolactinaemia and skin changes. The patient had a total hip replacement at a specialist orthopaedic hospital and is due to undergo radiotherapy to the femoral lesion and autologous stem cell transplantation.

\section{BACKGROUND}

Several hundred cases of POEMS (peripheral neuropathy, organomegaly, endocrinopathy, $M$ protein, skin changes) syndrome have been reported, but the condition is thought to be underdiagnosed. Patients are often misdiagnosed with myeloma or monoclonal gammopathy of undetermined significance (MGUS). ${ }^{1}$ POEMS syndrome can reliably be distinguished from other diseases if a thorough history is taken and examination performed. POEMS syndrome presenting with a pathological fracture has not been reported previously. As there are no randomised control trials on this rare paraneoplastic syndrome, current management of POEMS is based on case reports. Hence, more information on POEMS syndrome is needed so that evidence-based treatment can be given for this complex multisystem disorder.

\section{CASE PRESENTATION}

A 40-year-old Caucasian man presented to the accident and emergency department with severe pain in his right hip, which came on suddenly after tripping on a pavement kerb. $\mathrm{He}$ denied falling and was unable to weight bear. Peripheral neuropathy had been diagnosed in 2007 when he developed bilateral foot drop, paraesthesia of his feet and erectile dysfunction. Since then the paraesthesia had progressed proximally to his knees.

The patient was in severe pain and his right leg was shortened and externally rotated. The quadriceps were wasted bilaterally, his feet were in splints for his foot drop and there were multiple raised erythematous papules on his skin. The greater trochanter was tender and he was unable to move the right hip. The left leg moved normally. Heart sounds were normal and chest was clear on auscultation. There was obvious splenomegaly but no other abdominal abnormality. On rectal examination anal tone was normal. Neurological examination of the cranial nerves and upper limbs was normal. Tone in the lower limbs was increased bilaterally. It was not possible to fully assess power due to the patient's hip pain, however, power was grade five bilaterally in the upper limb and grade four in the left leg. Lower limb reflexes were normal. Plantars were downward bilaterally. Sensation was reduced in the L4-S1 region. Vibration sense, temperature, nociception and 2-point discrimination were impaired in this region.

\section{INVESTIGATIONS}

Radiographs of the hip revealed a pathological comminuted intertrochanteric fracture of the proximal right femur (figures 1 and 2). No additional lesions were found on skeletal survey. MRI showed a destructive lesion in the proximal femur, expanding the bone with a well-defined sclerotic margin. CT and positron emission tomography scans showed a lytic lesion in the right femur with marginal sclerosis which was fluorodeoxyglucose-avid (figures 2 and 3). An enlarged spleen $(17.4 \mathrm{~cm})$ was also evident on CT. Urine was negative for Bence-Jones protein. Serum immunofixation was consistent with immunoglobulin $G \lambda$ monoclonal gammopathy. Laboratory analysis revealed a normal full blood count, urea and electrolytes, liver function and thyroid function tests. Plasma glucose and haemoglobin A1c were normal. Blood tests revealed hypotestosteronaemia and hyperprolactinaemia.

The lesion was biopsied under CT guidance and found to be a plasmacytoma, $\lambda$ chain restricted.

\section{DIFFERENTIAL DIAGNOSIS}

The diagnosis of POEMS syndrome was made by a combination of history and examination findings. The presence of a pathological fracture, splenomegaly, skin changes, prolactinaemia, erectile dysfunction and peripheral neuropathy in a young male suggested a multisystem disorder. The diagnosis of multiple myeloma seemed unlikely given that no oligoclonal bands were seen on immune electrophoresis, urine Bence-Jones protein was negative and calcium was 


\section{BMJ Case Reports}

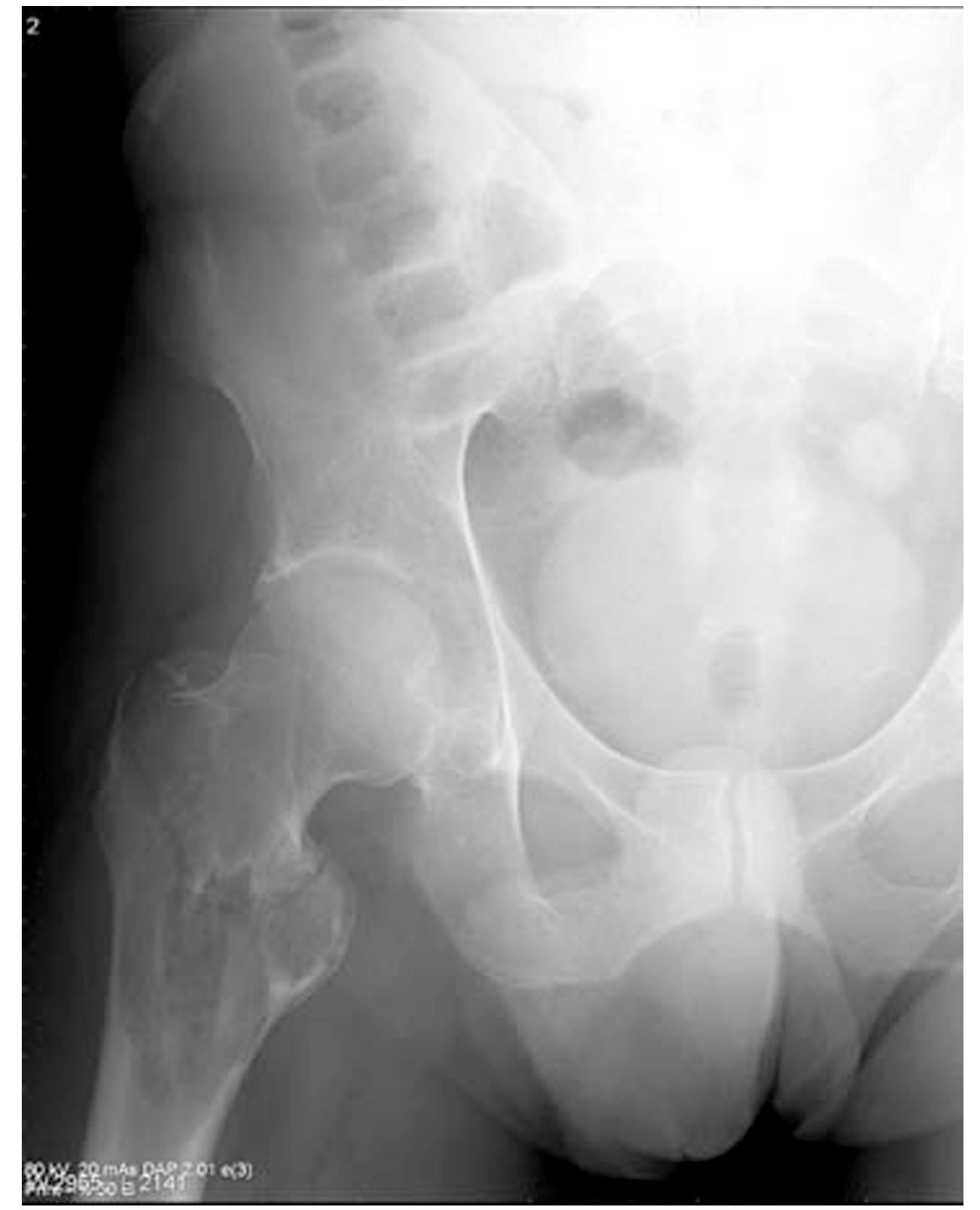

Figure 1 Radiograph of the proximal right femur. There is an intertrochanteric pathological fracture through a lytic lesion in the femur. There is well-defined endosteal scalloping of the femur and a sclerotic margin is seen medially to the lesion.

normal. In addition, classic multiple myeloma has never been reported in association with POEMS. ${ }^{2}$ The presence of peripheral neuropathy made the diagnosis of myeloma less likely as $50 \%$ of patients with osteosclerotic myeloma have peripheral neuropathy, while this occurs in only $1-8 \%$ of patient with multiple myeloma. ${ }^{3}{ }^{4}$ MGUS and Waldenstrom's macroglobulinaemia both result in the presence of an $\mathrm{M}$ protein on electrophoresis but, unlike POEMS, they are not associated with symptoms of end organ damage such as anaemia and organomegaly. ${ }^{5}$ Extensive imaging did not reveal a primary carcinoma to suggest that the pathological fracture was caused by a bony metastasis.

\section{OUTCOME AND FOLLOW-UP}

The patient was transferred to a specialist orthopaedic hospital and had a total hip replacement. He made a good recovery and is due to undergo radiotherapy to the femoral lesion and autologous stem cell transplantation.

\section{DISCUSSION}

Also known as Crow-Fukase syndrome, peculiar progressive polyneuritis syndrome or Takatsuki syndrome, POEMS syndrome is a rare multisystem syndrome associated with plasma cell dyscrasia that consists of the following features: polyneuropathy, organomegaly, endocrino- 


\section{BMJ Case Reports}

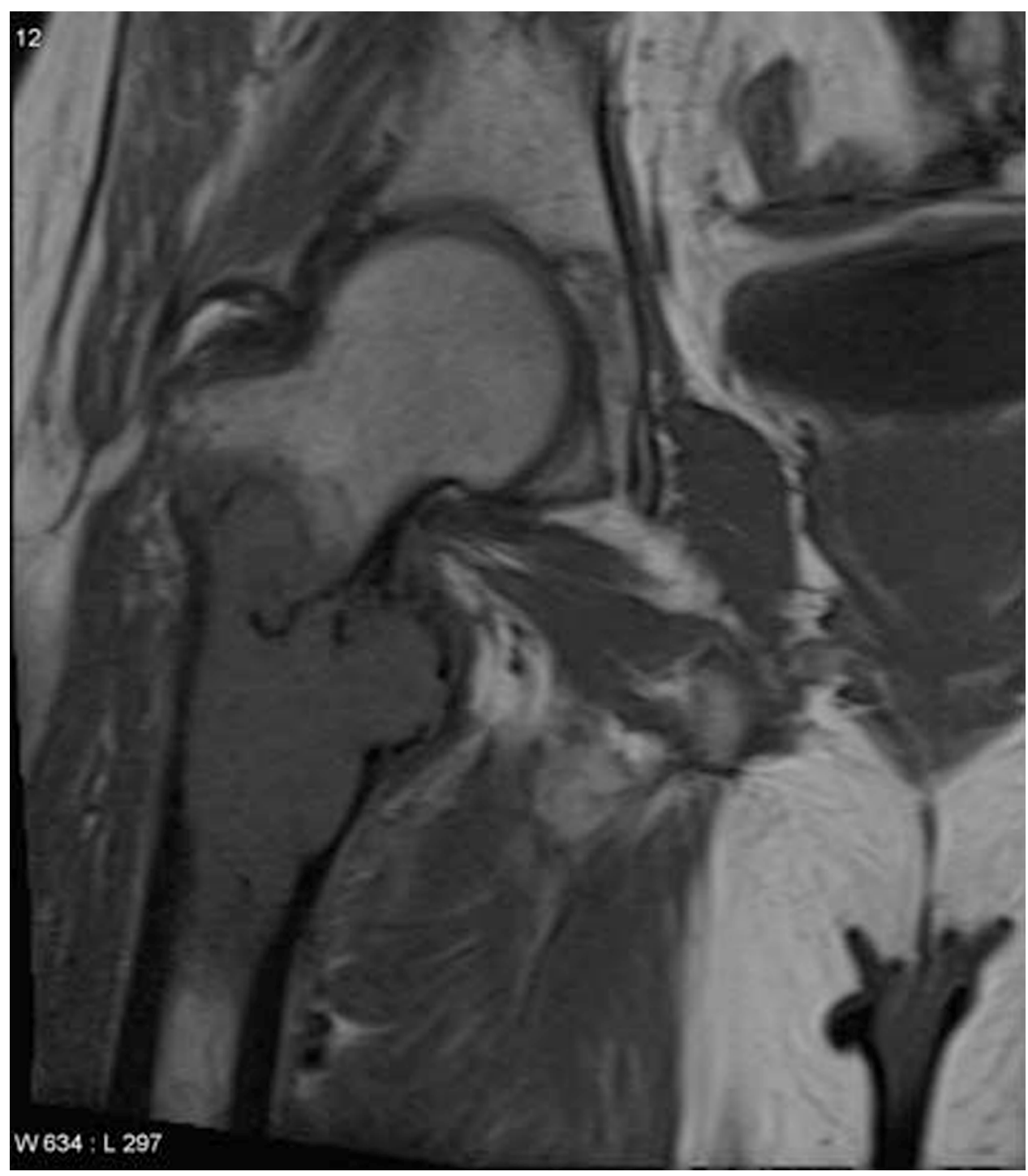

Figure 2 Coronal T1 weighted image showing a pathological fracture through the tumour in the proximal right femur. There is an intermediate signal tumour in the bone with some expansion of femur and endosteal scalloping. There is marginal sclerosis around the margins of the tumour, most obvious medially. There is a very small extraosseous mass at the medial margin of the tumour, closely related to the lesser trochanter.

pathy, monoclonal gammopathy and skin changes. This syndrome was first discovered in 1938 following Scheinker's autopsy of a 39-year-old man with plasmacytoma, sensorimotor polyneuropathy and patches of skin hyperpigmentation. ${ }^{3}$ The term was later coined by Bardwick et al in $1980 .^{6}$ Several hundred cases of POEMS syndrome have been reported, but the incidence is thought to be greater. Peak incidence occurs at age 50-60, and progressive peripheral neuropathy is the predominant feature. The 5 -year survival rate is approximately $60 \%$, which is greater than that of multiple myeloma. ${ }^{8}$ The number of POEMS features does not correlate with survival, however, and the presence of respiratory symptoms is associated with a poorer outcome. ${ }^{9}$ Within 2 years of diagnosis, approximately $25 \%$ of patients develop respiratory symptoms, including restrictive lung disease, impaired diffusion of carbon monoxide and pulmonary hypertension. ${ }^{9} 10$
The mechanism by which plasma cells cause POEMS syndrome is not fully understood, but it is thought to involve elevations in vascular endothelial growth factor (VEGF), interleukin 6 (IL6), tumour necrosis factor- $\alpha$ and IL1 $\beta .^{2}$ There is no definite diagnostic test for POEMS, although a raised vascular VEGF is usually confirmatory and correlates with disease activity. ${ }^{7}$ VEGF is present in platelets and megakaryocytes and is responsible for increasing vascular permeability and angiogenesis. ${ }^{11}$ However, other mechanisms may be involved as studies using bevacizumab, a monoclonal antibody directed against VEGF, have had variable results. ${ }^{11}$

As there are no criteria to define POEMS syndrome, diagnosis can be difficult. Most authors agree that the presence of two major and at least one minor criterion are confirmatory. ${ }^{9}$ The major criteria are monoclonal plasma cell proliferative disorder and chronic inflammatory demyelinating 


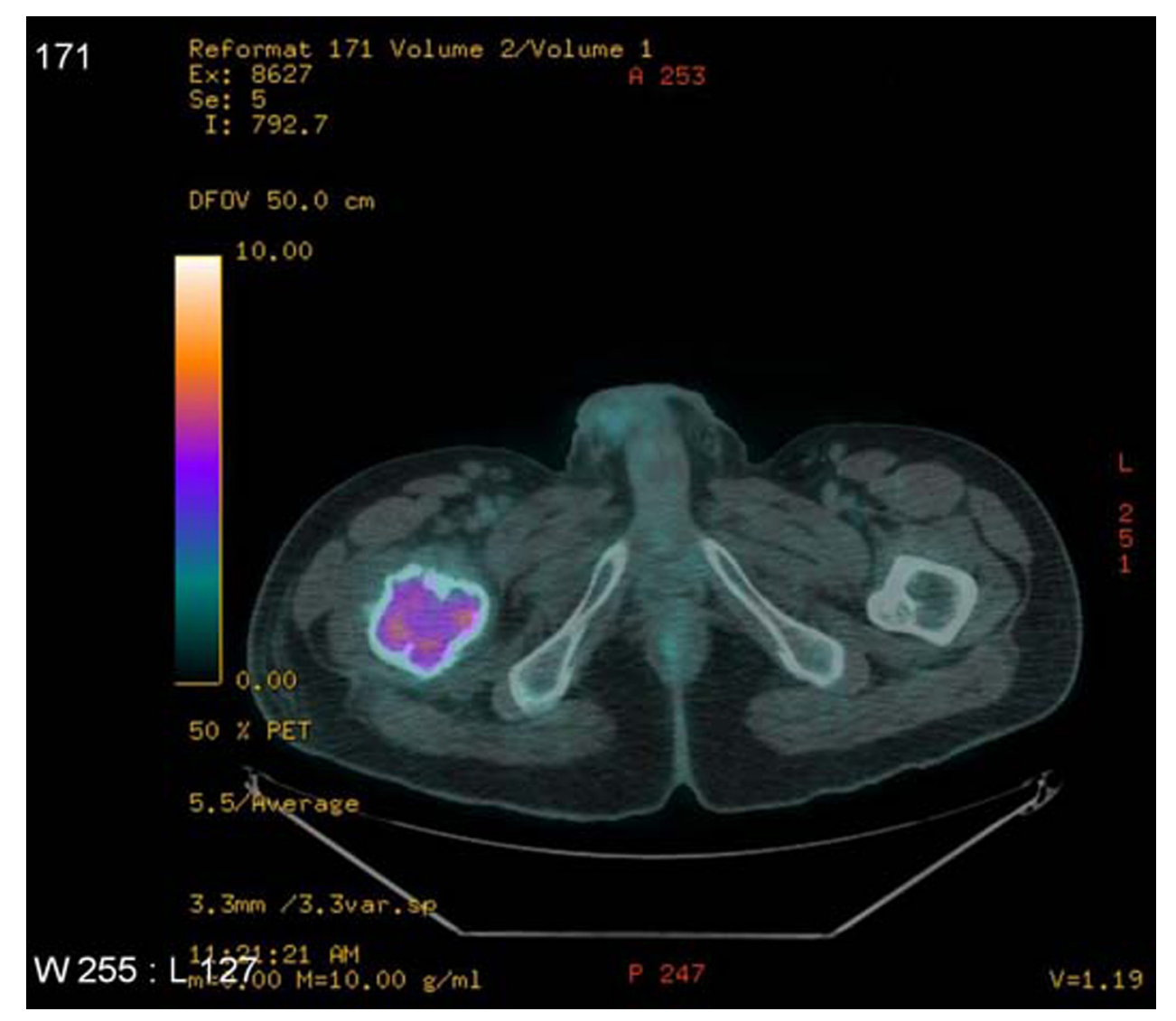

Figure 3 Fluorodeoxyglucose-positron emission tomography/CT image. There is high metabolite avidity in the tumour within the femur. No other avid lesions were seen.

polyneuropathy. ${ }^{6}{ }^{10}$ Minor criteria include sclerotic bone lesions, Castleman's disease, papilloedema, organomegaly, endocrinopathy peripheral oedema and ascites. ${ }^{79} 12$ Castleman's disease is characterised by giant and angiofollicular lymph node hyperplasia. ${ }^{7}$ Clinical features associated with POEMS include clubbing, weight loss, thrombocytosis and polycythaemia. ${ }^{9}$ The polyneuropathy typically spreads proximally and motor symptoms predominate.? Skin changes include haemangiomata, skin thickening, hyperpigmentation, hypertrichosis, white nails and clubbing. ${ }^{13}$

As POEMS syndrome is a multisystem disorder, a thorough history and full systems examination is required. Aside from baseline blood tests, useful blood tests to identify endocrine anomalies include luteinising hormone, follicle stimulating hormone, prolactin, parathyroid hormone, thyroid function tests, testosterone, oestradiol, cortisol, VEGF and fasting blood glucose. ${ }^{10}$ Due to the high incidence of respiratory features in POEMS patients, pulmonary function tests should be performed. ${ }^{10}$ Serum electrophoresis is needed to detect the classical $\lambda$-restricted $M$ protein. ${ }^{7}$ CT and MRI imaging help to differentiate the nature of bony lesions. Bony lesions associated with POEMS syndrome can appear sclerotic, lytic with a sclerotic edge or a have a mixed 'soap bubble' appearance. ${ }^{7}$ A full skeletal survey is required in order to ascertain whether the lesion is solitary. ${ }^{10}$ The lesion should be biopsied to determine the nature of the lesion as over $95 \%$ of patients with POEMS have a monoclonal $\lambda$ plasmacytoma. ${ }^{10}$
Most patients have multiple endocrine abnormalities. ${ }^{7}$ Endocrinopathies commonly associated with POEMS include hypogonadism, hypothyroidism, diabetes mellitus, adrenal insufficiency, hyperprolactinaemia and hypoparathyroidism. ${ }^{9}$ Our patient had a history of erectile dysfunction, hyperprolactinaemia and testosterone deficiency. It is possible that the patient's erectile dysfunction was secondary to hyperprolactinaemia induced hypogonadism.

Treatment of the underlying plasmacytoma is the major therapeutic approach in POEMS. Radiotherapy is indicated if there is a solitary plasmacytoma, and chemotherapy if there are multiple lesions. ${ }^{10}$ Other treatment options include peripheral blood stem cell transplantation, glucocorticoids and low-dose alkylating agents. ${ }^{7}$ Autologous peripheral blood stem cell transplantation has been trialled in a small proportion of POEMS patients where it has improved the symptoms of neuropathy, skin changes and lung function tests and reduced VEGF levels. ${ }^{14}$ Interestingly, patients with lymphadenopathy and splenomegaly were more likely to have post-transplant complications. ${ }^{14}$

POEMS syndrome is a rare paraneoplastic disorder comprising peripheral neuropathy, organomegaly, endocrinopathy, $M$ protein and skin changes. This is the first reported case of POEMS syndrome presenting with a pathological fracture. The patient had a hip replacement at a specialist orthopaedic hospital and is due to undergo radiotherapy to the femoral lesion. 


\section{Learning points}

- Pathological fractures in middle aged men are usually due to bony metastases.

- Taking a detailed medical history and performing a full systems examination make it easier to diagnose paraneoplastic syndromes.

- More research is needed into effective treatments in POEMS syndrome as current management relies on limited studies.

Acknowledgements This work was undertaken at UCLH/UCL, which receives funding from the Department of Health's NIHR Comprehensive Biomedical Research Centre funding scheme. The views expressed in this publication are those of the authors and not necessarily those of the UK Department of Health.

Competing interests None.

Patient consent Obtained.

\section{REFERENCES}

1. Dispenzieri A. POEMS Syndrome. Hematology Am Soc Hematol Educ Program 2005:360-7.

2. Liang C, Gonzalez M, Patel R, et al. POEMS syndrome (polyneuropathy, organomegaly, endocrinopathy, monoclonal gammopathy, and skin changes). Dermatol Online J 2009;15:9.
3. Mangalik A, Veliath AJ. Osteosclerotic myeloma with polyneuropathy A case report. Cancer 1971;28:1040-5.

4. Reitan JB, Pape E, Fosså SD, et al. Osteosclerotic myeloma with polyneuropathy. Acta Med Scand 1980;208:137-44.

5. Rajkumar SV, Dispenzieri A, Kyle RA. Monoclonal gammopathy of undetermined significance, Waldenstr $m$ macroglobulinemia, AL amyloidosis, and related plasma cell disorders: diagnosis and treatment. Mayo Clin Proc 2006;81:693-703

6. Bardwick PA, Zvaifler NJ, Gill GN, et al. Plasma cell dyscrasia with polyneuropathy, organomegaly, endocrinopathy, M protein, and skin changes: the POEMS syndrome. Report on two cases and a review of the literature. Medicine (Baltimore) 1980;59:311-22.

7. Dispenzieri A. POEMS syndrome. Blood Rev 2007;21:285-99.

8. Miralles GD, O'Fallon JR, Talley NJ. Plasma-cell dyscrasia with polyneuropathy. The spectrum of POEMS syndrome. N Engl J Med 1992;327:1919-23.

9. Dispenzieri A, Kyle RA, Lacy MO, et al. POEMS syndrome: definitions and long-term outcome. Blood 2003;101:2496-506.

10. Dispenzieri A, Gertz MA. Treatment of POEMS syndrome. Curr Treat Options Oncol 2004;5:249-57.

11. Watanabe 0, Arimura K, Kitajima I, et al. Greatly raised vascular endothelial growth factor (VEGF) in POEMS syndrome. Lancet 1996;347:702.

12. Gandhi GY, Basu R, Dispenzieri A, et al. Endocrinopathy in POEMS syndrome: the Mayo Clinic experience. Mayo Clin Proc 2007;82:836-42.

13. Kuwabara S, Dispenzieri A, Arimura K, et al. Treatment for POEMS (polyneuropathy, organomegaly, endocrinopathy, M-protein and skin changes) syndrome. Cochrane database of Syst Rev 2008;4:CD006828.

14. Dispenzieri A, Lacy MQ, Hayman SR, et al. Peripheral blood stem cell transplant for POEMS syndrome is associated with high rates of engraftment syndrome. European J Haemato/2008;80:397-406.

\footnotetext{
This pdf has been created automatically from the final edited text and images.

Copyright 2010 BMJ Publishing Group. All rights reserved. For permission to reuse any of this content visit http://group.bmj.com/group/rights-licensing/permissions.

BMJ Case Report Fellows may re-use this article for personal use and teaching without any further permission.

Please cite this article as follows (you will need to access the article online to obtain the date of publication).

Livingston J, Cobiella C, Hall-Craggs MA. POEMS syndrome - a unique presentation of a rare paraneoplastic syndrome. BMJ Case Reports 2010;

10.1136/bcr.09.2010.3324, date of publication

Become a Fellow of BMJ Case Reports today and you can:

- Submit as many cases as you like

- Enjoy fast sympathetic peer review and rapid publication of accepted articles

- Access all the published articles

- Re-use any of the published material for personal use and teaching without further permission

For information on Institutional Fellowships contact consortiasales@bmjgroup.com

Visit casereports.bmj.com for more articles like this and to become a Fellow
} 